\title{
TEMAS E TENDÊNCIAS DAS PESQUISAS EM BACIAS HIDROGRÁFICAS NO ÂMBITO DO SIMPÓSIO BRASILEIRO DE GEOGRAFIA FÍSICA APLICADA
}

\author{
Francisco Jonh Lennon Tavares da Silva ${ }^{(a)}$; Cláudia Maria Sabóia de Aquino ${ }^{(b)}$ \\ (a) Discente do curso de Mestrado em Geografia da Universidade Federal do Piauí; lennonufpi@hotmail.com \\ (b) Doutora em Geografia. Professora Adjunta da Universidade Federal do Piauí; cmsaboia@ gmail.com
}

\section{EIXO: BACIAS HIDROGRÁFICAS E RECURSOS HÍDRICOS: ANÁLISE, PLANEJAMENTO E GESTÃO}

\begin{abstract}
Resumo
Objetivou-se avaliar a adoção da bacia hidrográfica como âncora de análise no contexto da produção científica do Simpósio Brasileiro de Geografia Física Aplicada. Para tanto, realizou-se um balanço dos estudos publicados no simpósio em epígrafe, considerando as últimas quatro edições (2009; 2011; 2013 e 2015). Inicialmente, quantificaram-se os trabalhos que adotam a bacia hidrográfica como recorte espacial e, em um segundo momento, foi feita uma categorização temática das pesquisas, seguida por uma reflexão a respeito dos objetivos e finalidades destes estudos. Dentre as temáticas mais trabalhadas, citam-se: mapeamento do uso da terra, degradação ambiental, padrões de drenagem e compartimentação do relevo, gestão de recursos hídricos, geoconservação, vulnerabilidade/riscos socioambientais, educação ambiental e balanço hidroclimático. A partir da análise dos estudos publicados nos anais dos SBGFAs selecionados, o artigo espera contribuir para a discussão em torno da importância atribuída à bacia hidrográfica enquanto unidade integrada de investigação, planejamento e gestão ambiental no cerne das tendências da pesquisa geográfica brasileira.
\end{abstract}

Palavras-chave: Bacia Hidrográfica; Geografia Física; Relação Sociedade-Natureza; Produção do Conhecimento.

\section{Introdução}

O estudo da natureza sempre fez parte do escopo da Geografia. Da mesma forma, Ross (2006) observa que não existe Geografia sem sociedade, posto ser com base na estrutura social do espaço que se elaboram as investigações geográficas. Atualmente, é cada vez maior o interesse dos geógrafos em privilegiar o estudo integrado da relação sociedade-natureza, cujos produtos científicos podem se reverter em subsídios ao planejamento ambiental e ao ordenamento territorial.

Nessa perspectiva, a meta da análise geográfica integrativa consiste em obter um conjunto de informações sobre como a sociedade transforma o espaço, de forma a balizar os programas de planejamento e gestão ambiental no contexto de um determinado espaço territorial, seja para conservar, preservar ou recuperar a natureza degradada ou em vias de degradação e, ao mesmo tempo, promover o desenvolvimento econômico e social em bases sustentáveis (ROSS, 2006).

Nesse contexto, o sistema bacia hidrográfica comporta-se como um interessante recorte espacial para a análise geográfica da relação sociedade-natureza. Enquanto um dos componentes dos sistemas 
naturais, a bacia hidrográfica caracteriza-se como um sistema aberto que reúne em seus limites um variado conjunto de elementos que interagem de forma integrada e complexa (CHRISTOFOLETTI, 1980).

Dessa forma, ao se trabalhar a bacia hidrográfica como unidade físico-territorial dos estudos geográficos integrativos torna-se de fundamental importância compreender que a dinâmica dos sistemas ambientais e dos sistemas socioeconômicos mantém estreita relação. Assim sendo, descartam-se as análises setorizadas que avaliam somente informações parciais e desconectadas.

Com efeito, os estudos em bacias hidrográficas visam sistematizar os conhecimentos sobre a natureza e sua estrutura, os elementos que a compõe, a maneira pela qual uns influenciam os demais, o papel de cada um deles na dinâmica geral da unidade ambiental e como a sociedade os modifica, criando novas estruturas e dinâmicas ambientais na organização espacial do território (SOUZA; CORRÊA, 2013).

Neste viés de análise, faz-se necessária uma abordagem sistêmica dessa unidade físico-territorial, uma vez que o alcance explicativo da Teoria Geral dos Sistemas possibilita a compreensão integrada da dinâmica ambiental e autoriza a avaliação dos efeitos originados por eventuais intervenções (CHRISTOFOLETTI, 1999).

Rodriguez, Silva e Cavalcanti (2004) assinalam que a concepção sistêmica consiste numa abordagem em que qualquer diversidade da realidade estudada (objetos, propriedades, fenômenos) pode ser concebida como uma unidade integrada, a qual se manifesta através de categorias sistêmicas, tais como: estrutura, elementos, relações e transformações.

Ao ponderar sobre o significado da concepção sistêmica para os estudos em bacias hidrográficas, Nascimento (2011) salienta que a bacia hidrográfica comporta-se como um sistema complexo, composto por elementos e variáveis interligados por meio de ciclos de transformação, autoajuste, dissipação e autoorganização. As relações mútuas entre seus elementos possibilitam a análise integrada do ambiente, auxiliando a avaliação dos aspectos físicos, econômicos e sociais. Por essa lente, a unicidade, integridade e complexidade do sistema bacia hidrográfica verificam-se na interação entre os elementos naturais e sociais que a constituem.

Patrocinado pelos preceitos da abordagem sistêmica, o geógrafo coloca-se um passo à frente da simples descrição, passando a lidar com os encargos da explicação e da avaliação prescritiva, na perspectiva de vislumbrar os usos tendenciais e os cenários degradacionais correspondentes, oferecendo informações objetivadas por uma grade teórica mais consistente e abrangente sobre a dinâmica socioambiental, em que a bacia hidrográfica revela-se como objeto de análise e reflexão (CUNHA; GUERRA, 2006).

A partir destas considerações, a busca para entender o funcionamento da bacia hidrográfica numa perspectiva sistêmica tem se refletido no crescente número de estudos que a adotam como célula de 
análise. Para a Geografia, em específico, o sistema bacia hidrográfica salienta-se como unidade básica para as pesquisas comprometidas com a análise integrada da relação sociedade-natureza.

Diante disso, este artigo teve como objetivo avaliar a importância da bacia hidrográfica como recorte espacial privilegiado para os estudos geográficos, evidenciando e discutindo os temas-problemas mais trabalhados no âmbito da produção do conhecimento das últimas quatro edições do Simpósio Brasileiro de Geografia Física Aplicada (2009, 2011, 2013 e 2015).

Metodologicamente, a discussão foi desenvolvida a partir de revisão bibliográfica concernente aos conceitos básicos que fundamentam as pesquisas sobre bacias hidrográficas. Para distinguir as categorias temáticas evidenciadas nos artigos, foram considerados o tema-problema, os objetivos e os resultados empíricos apresentados nos resumos e trabalhos completos publicados nos anais do simpósio em tela.

\section{A bacia hidrográfica como unidade de estudo no âmbito da produção científica do Simpósio Brasileiro de Geografia Física Aplicada (2009; 2011; 2013; 2015).}

Nesta seção, exibe-se inicialmente um panorama quantitativo referente ao total de trabalhos divulgados nos anais das edições do SBGFA analisadas, seguido pelo percentual de artigos que adotam a bacia hidrográfica (B. H.) como âncora de análise e reflexão. Posteriormente, apresenta-se uma categorização dos enfoques temáticos visualizados nestes estudos, a partir dos quais se desenvolveu a discussão dos dados levantados para o período (Tabela 1).

Tabela 1 - Total de trabalhos publicados nos SBGFAs e percentual de adoção da B. H. como unidade de análise.

\begin{tabular}{l|c|c|c}
\hline Edições do SBGFA analisadas & $\begin{array}{c}\mathbf{N}^{\mathbf{0}} \text { de trabalhos } \\
\text { publicados nos } \\
\text { anais }\end{array}$ & $\begin{array}{c}\mathbf{N}^{\mathbf{0}} \text { de trabalhos } \\
\text { que adotam a B. H. } \\
\text { como âncora de } \\
\text { análise }\end{array}$ & $\%$ \\
\hline XIII SBGFA (Viçosa/MG, 2009) & 978 & 258 & $26,3 \%$ \\
\hline XIV SBGFA (Dourados/MS, 2011) & 982 & 222 & $22,5 \%$ \\
\hline XV SBGFA (Vitória/ES, 2013) & 633 & 176 & $27,8 \%$ \\
\hline XVI SBGFA (Teresina/PI, 2015) & 621 & 153 & $24,6 \%$ \\
\hline
\end{tabular}

Fonte: SBGFA (2009; 2011; 2013; 2015).

Organização dos autores (2017). 
A Figura 1 apresenta a evolução no uso da bacia hidrográfica no contexto do Simpósio Brasileiro de Geografia Física Aplicada (2009; 2011; 2013; 2015).

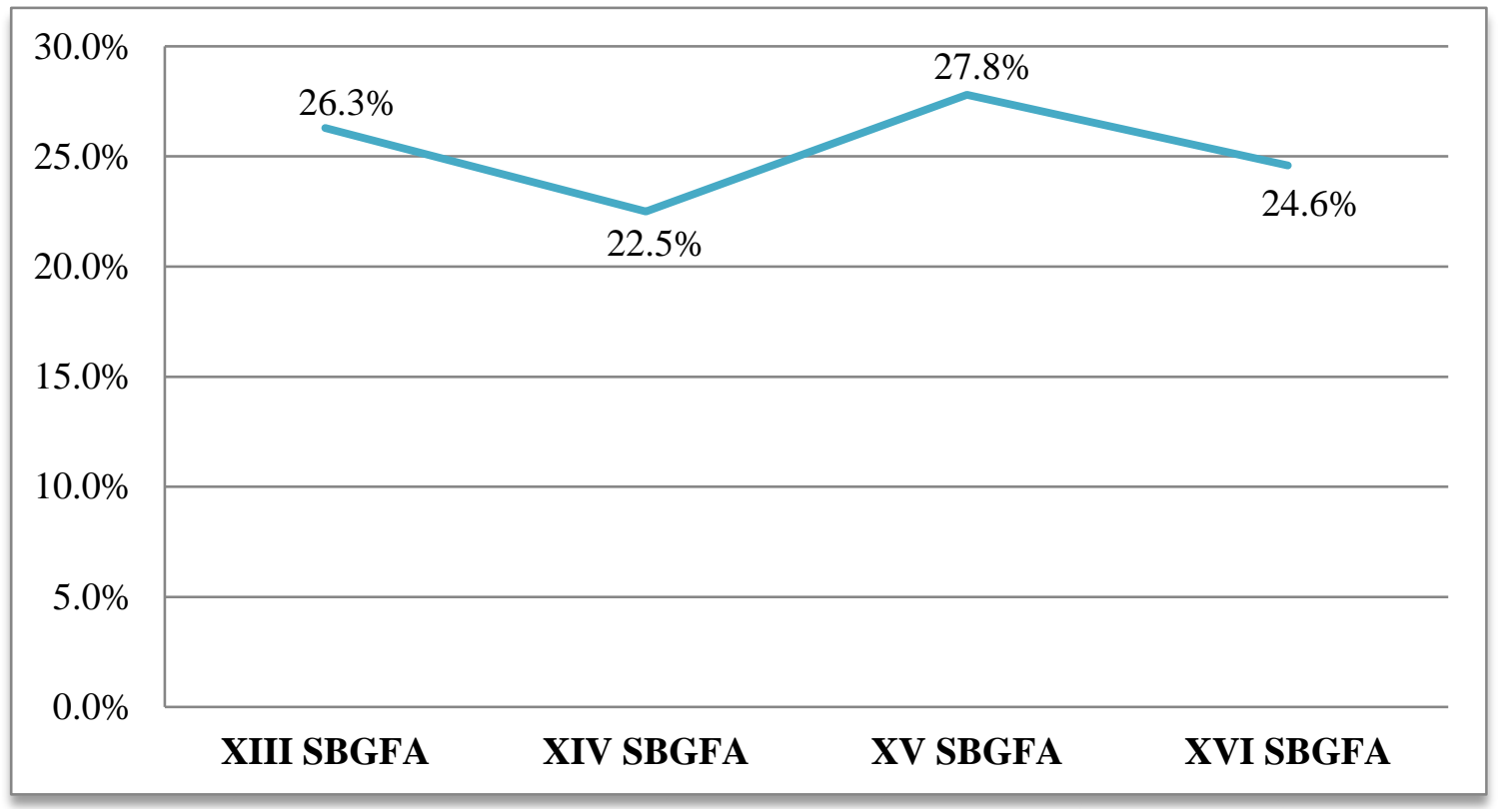

Figura 1 - Adoção da bacia hidrográfica nos SBGFAs: comportamento percentual nas últimas edições. Fonte: SBGFA (2009; 2011; 2013; 2015).

Organização dos autores (2017).

As informações apresentadas na Tabela 1 e na Figura 1 inspiram cautela interpretativa, mas permitem algumas considerações preliminares. Destaca-se, primeiramente, que o número total de artigos publicados nas edições do SBGFA analisadas foi bastante expressivo, fato que certamente tem reflexos na produção do conhecimento, atestando o cenário de crescente interesse dos estudiosos do espaço geográfico em publicar as suas pesquisas.

Em segundo lugar, ressalta-se que, embora elevado, o número de artigos divulgados nos anais dos SBGFAs avaliados mostrou-se variável no recorte temporal analisado, sobretudo entre as edições de 2011 e 2013, com uma queda de 35,5\%. Foram 349 produtos científicos a menos neste período. Entre as edições de 2013 e 2015 pôde-se observar a mesma tendência de declínio, embora bem menos expressiva, com um déficit de $1,8 \%$.

Todavia, a despeito da queda na produção científica verificada a partir da XV edição (2013), o número de estudos que adotam a bacia hidrográfica como âncora de análise e reflexão mostrou-se relativamente constante, variando entre 22,5\% (Dourados, 2011) e 27,8\% (Vitória, 2013) de aplicações em bacias hidrográficas. 
XVII Simpósio Brasileiro

de Geografia Fisica Aplicada

I Congresso Nacional de Geografia Física
OS DESAFIOS DA GEOGRAFIA FÍSICA NA FRONTEIRA DO CONHECIMENTO

Instituto de Geociências - Unicamp

Campinas - SP

28 de Junho à 02 de Julho de 2017

As pesquisas em bacias hidrografias publicadas nas edições do SBGFA analisadas notabilizam-se pela multiplicidade das temáticas e problemáticas postas em investigação empírica. São estudos concatenados, sobretudo, à complexa relação sociedade-natureza (Figuras 2, 3, 4 e 5).
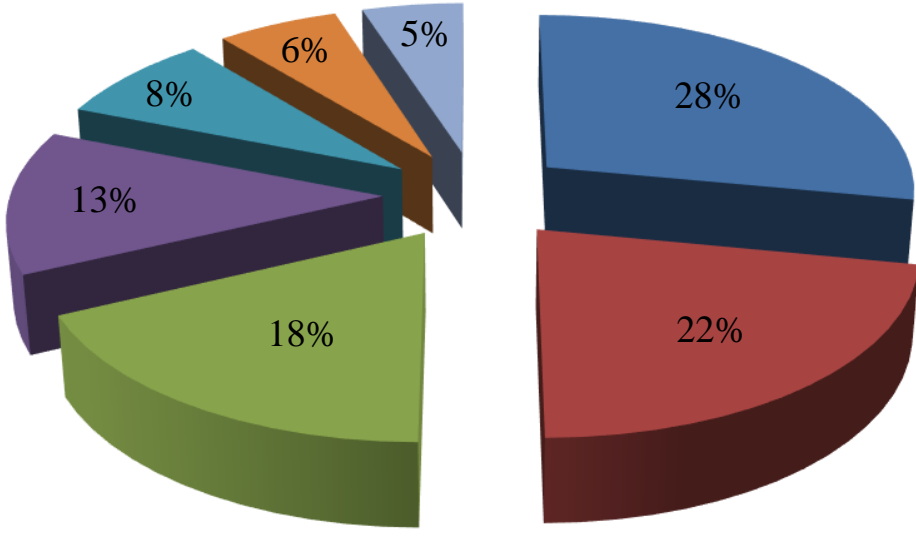

- Degradação ambiental

- Mapeamento do uso da terra

Padrões de drenagem e compartimentação do relevo

- Gestão de recursos hídricos

- Vulnerabilidade e riscos socioambientais

- Educação ambiental

Outros

Figura 2 - Tendências temáticas dos estudos em bacias hidrográficas (XIII SBGFA, Viçosa, 2009).

Fonte: XIII SBGFA (2009).

Organização dos autores (2017).

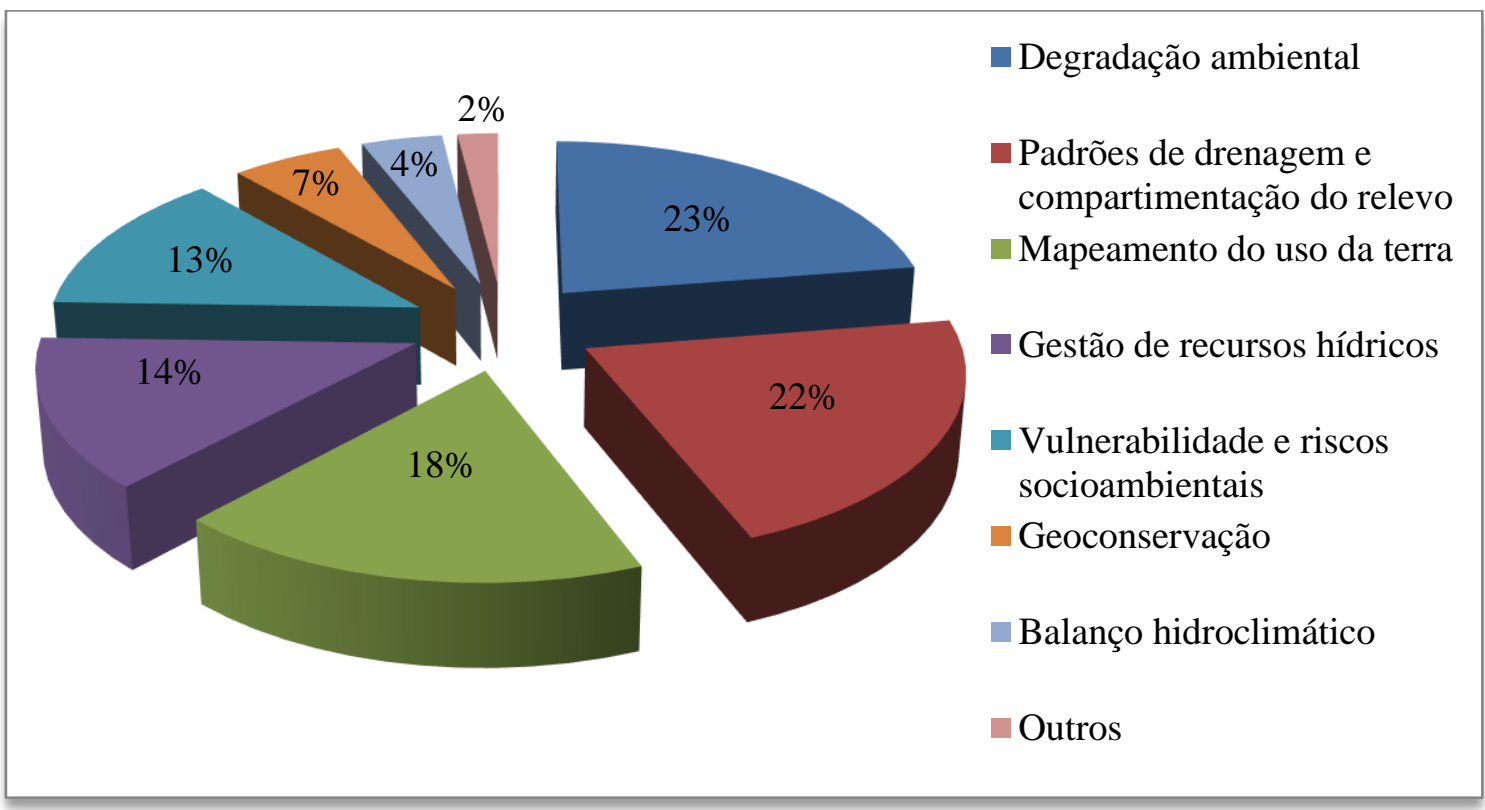

Figura 3 - Tendências temáticas dos estudos em bacias hidrográficas (XIV SBGFA, Dourados, 2011). Fonte: XIV SBGFA (2011).

Organização dos autores (2017). 


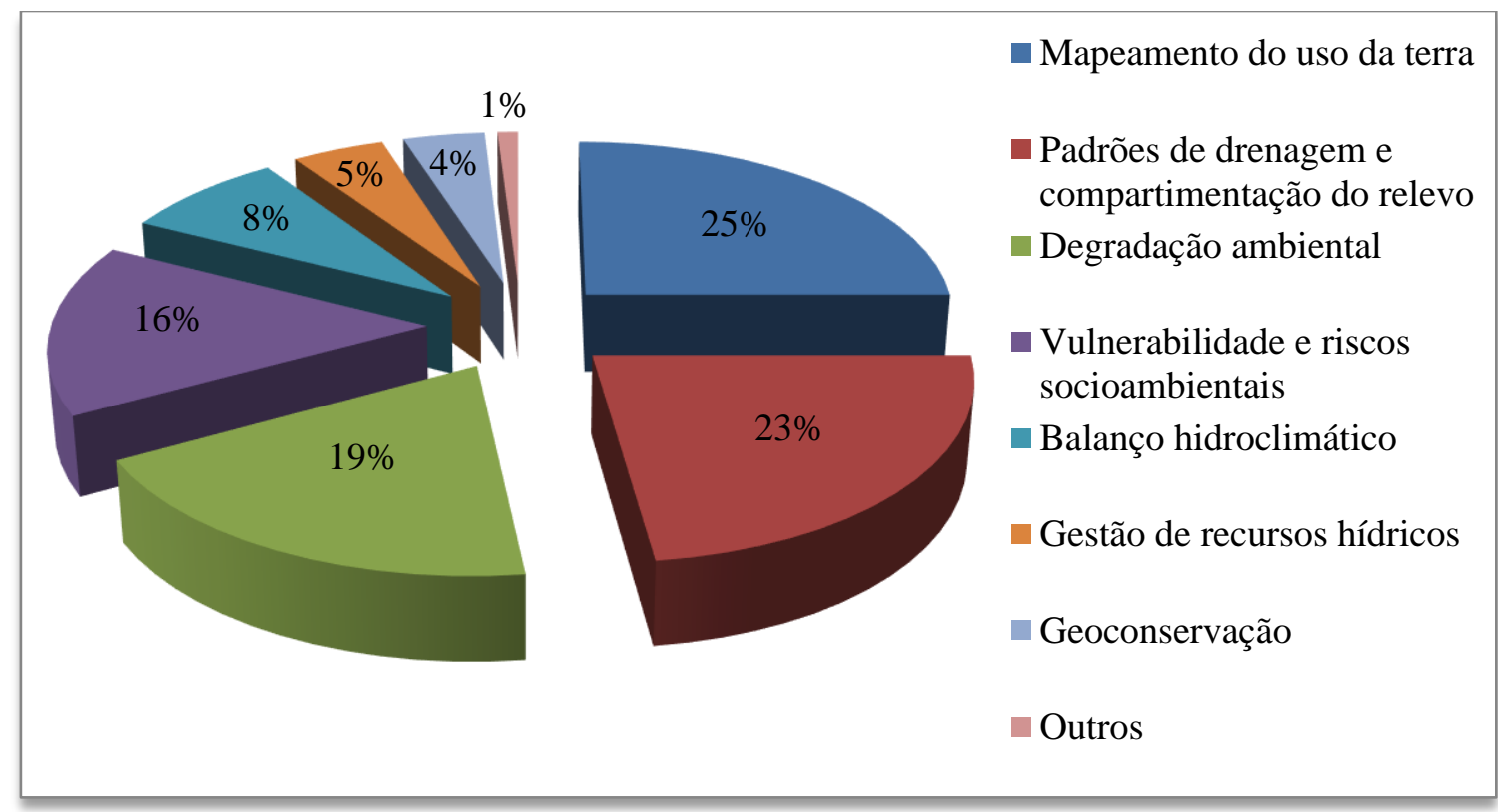

Figura 4 - Tendências temáticas dos estudos em bacias hidrográficas (XV SBGFA, Vitória, 2013).

Fonte: XV SBGFA (2013).

Organização dos autores (2017).

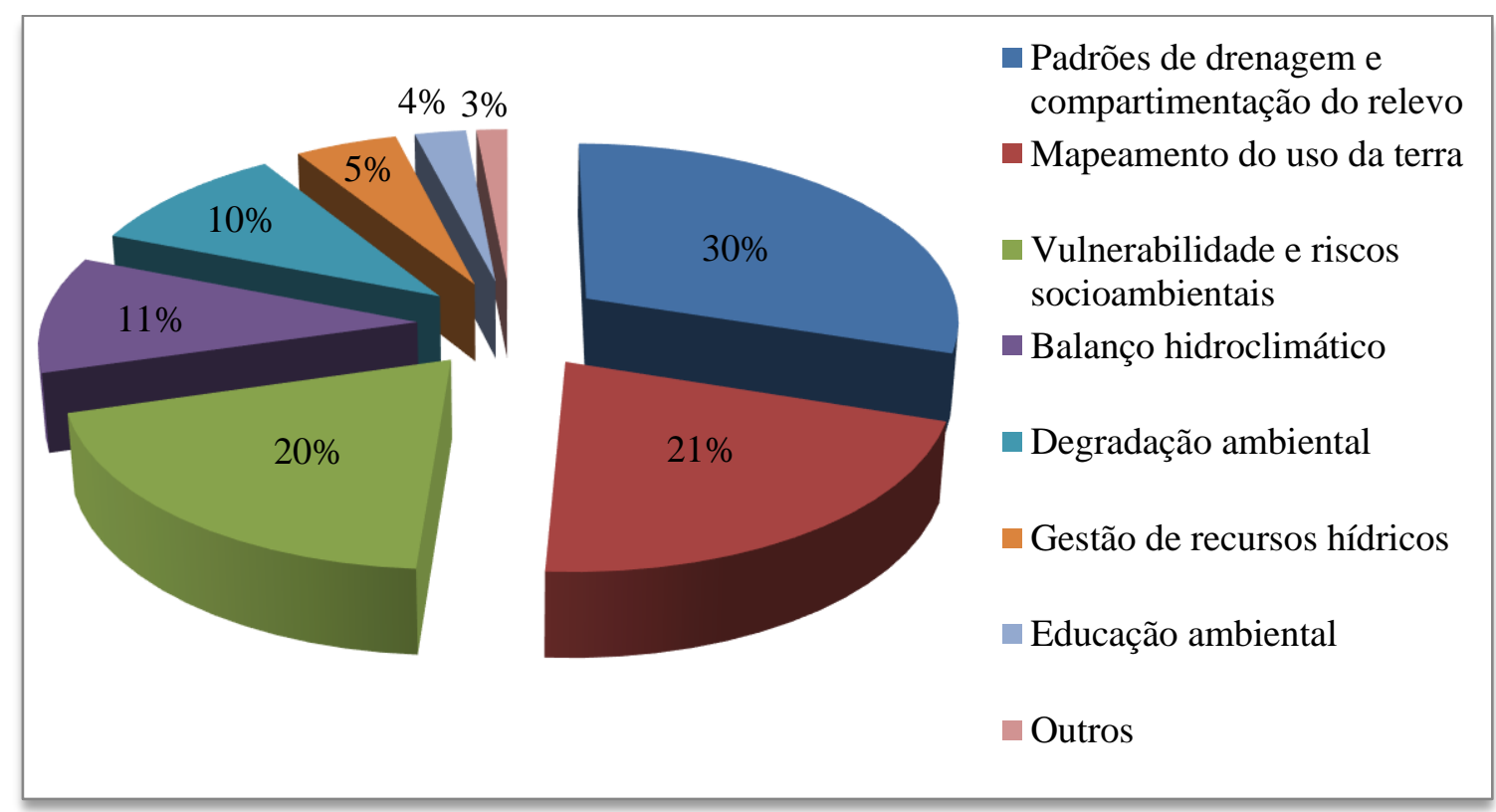

Figura 5 - Tendências temáticas dos estudos em bacias hidrográficas (XVI SBGFA, Teresina, 2015).

Fonte: XVI SBGFA (2015).

Organização dos autores (2017). 
Ao adotarem a bacia hidrográfica como âncora de análise e reflexão, os estudos desenvolvidos recentemente no Brasil reforçam que este sistema natural salienta-se como o recorte espacial mais adequado para os estudos geográficos integrativos. Este é, de fato, o argumento subjacente à literatura levantada ao longo destes últimos sete anos de produção científica do Simpósio Brasileiro de Geografia Física Aplicada.

E como salientado anteriormente, as pesquisas em bacias hidrográficas contemplam uma ampla gama de temas, despertados pelo interesse em problemáticas específicas sobre a dinâmica dos sistemas ambientais. Com efeito, os geógrafos se concentram em analisar os desdobramentos das interações bidirecionais entre os sistemas naturais e as atividades da sociedade, tendo por âncora de avaliação empírica a bacia hidrográfica.

Nesse contexto, destaca-se o interesse dos pesquisadores em analisar a dinâmica das atividades sociais sobre o seu ambiente, na ânsia de compreender as modificações impostas ao arranjo dos sistemas naturais. Como desdobramento, cita-se o significativo número de estudos sobre uso da terra, em que se observam as recorrentes recomendações de levantamento das potencialidades e limitações dos sistemas ambientais diante dos cenários tendenciais de exploração socioeconômica. A dinâmica de uso da terra é a expressão concreta das relações socioeconômicas em um dado território, destacando-se como uma questão-chave no âmbito das investigações em bacias hidrográficas.

Nesse sentido, compreender a diferenciação da apropriação da natureza torna-se importante, tendo em vista que as formas como a sociedade se apropria da natureza são distintas e, dependendo dos seus objetivos, finalidades e capacidade de intervenção, a apropriação pode ocorrer em desacordo com as limitações e potencialidades naturais, podendo eventualmente romper o equilíbrio dos sistemas ambientais (ROSS, 2006). Assim sendo, o mapeamento e caracterização das tipologias de uso da terra têm grande importância diante das questões sobre desenvolvimento sustentável e ordenamento territorial.

A análise geográfica em bacias hidrográficas tem sido fundamental nos estudos relacionados à degradação ambiental. Áreas degradadas são aquelas que sofreram algum tipo de perturbação em sua integridade e condição de equilíbrio original, a ponto de afetar a dinâmica dos sistemas ambientais, com repercussões na qualidade de vida das sociedades (CHRISTOFOLETTI, 1999; CUNHA; GUERRA, 2006). Desmatamentos, aceleração de processos erosivos, lixiviação, contaminação do solo, poluição da água e estagnação das drenagens urbanas são alguns exemplos de focalizações temáticas no âmbito das pesquisas levantadas. Mais do que isso: são a constatação científica de como a relação sociedade-natureza se tornou problemática. 


\section{OS DESAFIOS DA GEOGRAFIA FÍSICA NA FRONTEIRA DO CONHECIMENTO \\ Instituto de Geociências - Unicamp \\ Campinas - SP \\ 28 de Junho à 02 de Julho de 2017}

O interesse dos pesquisadores em relação à geoconservação se mostrou presente no quadro das tendências temáticas. Perpassa as preocupações dos estudiosos do assunto não apenas a necessidade de conservação da natureza como recurso, mas principalmente enquanto patrimônio da humanidade. Nesta perspectiva, os geógrafos procuram discutir e propor novas formas de uso, preservação e conservação das potencialidades paisagísticas.

As bacias hidrográficas vêm sendo adotadas como áreas preferenciais para o planejamento e gestão dos recursos hídricos. A construção dessas pesquisas assenta-se na preocupação dos pesquisadores em verificar se as bacias hidrográficas vêm de fato adotando um modelo de gestão integrada, em que os componentes ambientais sejam compreendidos no âmbito de suas interações sistêmicas e em suas interrelações com a sociedade. O significativo percentual de estudos sobre a temática atesta que a bacia hidrográfica representa um importante instrumento de intervenção da política ambiental nacional e unidade de planejamento e gerenciamento dos recursos hídricos.

As discussões sobre vulnerabilidade e riscos ambientais emergem com destaque na atualidade (VEYRET, 2007; ALMEIDA, 2012). Isso se deve ao fato de que as mudanças impostas à organização do espaço geográfico reclamam a renovação das abordagens teóricas, conceituais e metodológicas com vistas à avaliação de como os diferentes ambientes respondem às diferentes formas de ocupação - as quais se mostram estampadas num modelo econômico desigual, muitas vezes inspirador de conflitos socioambientais. Nessa perspectiva, a Geografia se interessa pelos riscos e vulnerabilidades cuja compreensão assuma uma dimensão espacial; e onde a sociedade assuma ao mesmo tempo o papel de agressora e vítima do seu ambiente (VEYRET, 2007).

Com efeito, os estudos voltados às vulnerabilidades e riscos socioambientais procuram avançar no entendimento de como a ocupação desordenada dos sistemas ambientais pode acarretar processos naturais perigosos, sobretudo em espaços com alta vulnerabilidade, naturalmente mais susceptíveis a situações de riscos. São áreas ocupadas por populações dotadas dos piores indicadores sociais e econômicos (ALMEIDA, 2012). A ocupação indiscriminada de encostas ou planícies fluviais, por exemplo, gera cenários de maior vulnerabilidade a enchentes, inundações, deslizamentos, dentre outros processos desencadeadores de desastres.

Os balanços hidroclimáticos emergem com assiduidade no contexto da produção científica dos SBGFAs analisados, perfazendo um volume bastante significativo de investigações no âmbito deste "laboratório" natural que são as bacias hidrográficas. Estes estudos têm por objetivo precípuo a geração de banco de dados pluviométricos úteis à elaboração de mapeamentos básicos e temáticos daquelas áreas mais susceptíveis a processos erosivos ou de maior irregularidade hídrica, por exemplo. A contínua 
disponibilidade destas informações pode subsidiar os estudos com maiores pretensões, a exemplo daqueles voltados à gestão de recursos hídricos dentro de um contexto mais amplo de planejamento ambiental.

Trabalhada no contexto espacial da bacia hidrográfica, a educação ambiental assume papel fundamental na sociedade contemporânea, evocando o viés pedagógico da ciência geográfica e configurando um largo campo de atuação profissional. O pressuposto básico continua o mesmo para as pesquisas com esta temática: buscar a integração entre as questões inerentes à relação sociedade-natureza, através da construção de princípios e conceitos que estimulem nos jovens e adultos o desenvolvimento de práticas e relações mais sustentáveis com o seu ambiente cotidiano.

Embora a problemática ambiental, posta em evidência pelo modelo analítico sociedade-natureza, tenha dado a tônica na maioria dos estudos aplicados em bacias hidrográficas, devem ser reconhecidas aquelas aplicações que não vão necessariamente ao encontro deste nexo conceitual. São estudos que procuram levantar informações básicas sobre os padrões de drenagem e/ou buscam compartimentar as unidades de relevo, considerando diferentes escalas de tratamento, a fim de compreender o comportamento das formas e processos geomorfológicos frente à dinâmica hidrológica.

Cita-se como recorrente no cerne deste direcionamento temático a curiosidade dos pesquisadores em aplicar seus conhecimentos em geoprocessamento e ferramentas geotecnológicas correlatas. Mesmo que tais estudos não tenham como pressuposto contribuir para a análise de situações configuradoras de problemas ambientais, deve-se ressaltar que a análise da dinâmica dos sistemas fluviais numa perspectiva geomorfológica possibilita uma compreensão preliminar sobre a dinâmica dos sistemas ambientais.

Por fim, em relação às perspectivas analíticas visualizadas nos trabalhos publicados ao longo destas últimas edições do SBGFA, identificaram-se pelo menos três vieses:

$\checkmark \quad$ Estudo setorizado dos elementos constituintes da natureza (modelo Natureza-Natureza);

$\checkmark \quad$ Estudo integrado dos elementos da natureza, porém separado da sociedade (modelo Natureza/Sociedade);

$\checkmark \quad$ Estudo articulado dos elementos da natureza e da sociedade (modelo Natureza-Sociedade).

Para o conjunto das tendências temáticas evidenciadas nas Figuras 2, 3, 4 e 5 predominam os modelos Natureza/Sociedade e Natureza-Sociedade. Nesse sentido, constata-se a consolidação de uma nova perspectiva, em que está sendo cada vez mais privilegiado o estudo da dinâmica e funcionalidade da paisagem numa perspectiva integrativa, tendo por meta a avaliação dos novos arranjos dos sistemas ambientais decorrentes da apropriação da natureza pela sociedade.

Neste cenário de reavaliações teórico-metodológicas, a perspectiva socioambiental, sustentada por princípios sistêmicos, parte do pressuposto de que os problemas ambientais são essencialmente sociais; 
XVII Simpósio Brasileiro

de Geografia Física Aplicada

I Congresso Nacional

de Geografia Física
OS DESAFIOS DA GEOGRAFIA FÍSICA NA FRONTEIRA DO CONHECIMENTO

Instituto de Geociências - Unicamp

Campinas - SP

28 de Junho à 02 de Julho de 2017

que são resultantes da apropriação diferenciada da natureza pelas diferentes classes sociais. Para a ciência geográfica, esta "virada" de perspectiva pode eventualmente possibilitar uma aproximação mais exitosa entre as preocupações temáticas da Geografia Física e da Geografia Humana. Para tanto, são necessários mais avanços e resultados, tanto teóricos como empíricos. Nessa direção, a bacia hidrográfica se configura como recorte espacial ideal para o desenvolvimento de estudos geográficos integrativos.

\section{Considerações finais}

O objetivo principal deste artigo foi avaliar a importância da bacia hidrográfica como unidade territorial de estudo a partir do levantamento da produção do conhecimento no contexto de um dos mais importantes encontros científicos da Geografia nacional, qual seja: o Simpósio Brasileiro de Geografia Física Aplicada. A partir do recorte temporal delimitado foi possível trazer a relevo os temas-problemas mais trabalhados nas últimas edições do referido simpósio.

Como principal achado desta pesquisa, verificou-se o predomínio do viés da intervenção antrópica na natureza, donde se deriva o maior direcionamento dos estudos para a avaliação dos impactos ambientais no contexto das bacias hidrográficas brasileiras. Com este enfoque, cita-se o volumoso pacote de pesquisas sobre degradação ambiental.

Ainda no espectro das pesquisas interessadas na relação sociedade-natureza, destacaram-se aquelas direcionadas à dinâmica de uso da terra, gestão de recursos hídricos, vulnerabilidade e riscos socioambientais, balanço hidroclimático, geoconservação e educação ambiental. Cada uma destas focalizações levanta questionamentos relevantes, procurando oferecer respostas sobre como a sociedade pode promover uma ocupação equilibrada dos territórios.

Mesmo não assumindo imediato compromisso com a avaliação das vicissitudes socioambientais, foram quantitativamente significativos os estudos a respeito da funcionalidade dos sistemas ambientais naquilo de tange à dinâmica dos seus atributos físicos. No cerne deste modelo de análise, salientaram-se as pesquisas sobre o comportamento dos padrões de drenagem e os mapeamentos geomorfológicos.

Neste contexto de riqueza acadêmica - atestada pela multiplicidade dos temas e problemas de pesquisa; pelas intensas imbricações dos processos e elementos constituintes do espaço geográfico brasileiro; dos desafios ainda presentes no arcabouço teórico-metodológico da Geografia -, é que se explicita a dimensão e importância dos eventos científicos para o engrandecimento dessa ciência, tendo em vista a compreensão dos fenômenos geográficos em suas múltiplas escalas, considerando ainda as diversas abordagens teórico-metodológicas e conceituais disponíveis. 


\section{Referências bibliográficas}

ALMEIDA, L. Q. Riscos ambientais e vulnerabilidades nas cidades brasileiras: conceitos, metodologias e aplicações. São Paulo: Cultura Acadêmica, 2012.

CHRISTOFOLETTI, A. Geomorfologia. 2. ed. São Paulo: Edgard Blücher, 1980.

Modelagem de sistemas ambientais. São Paulo: Edgard Blücher, 1999.

CUNHA, S. B.; GUERRA, A. J. T. Degradação ambiental. In: GUERRA, A. J. T.; CUNHA, S. B. (Org.).

Geomorfologia e meio ambiente. 6. ed. Rio de Janeiro: Bertrand Brasil, 2006.

NASCIMENTO, F. R. Categorização de Usos Múltiplos dos Recursos Hídricos e Problemas Ambientais: Cenários e Desafios. In: MEDEIROS, C. N.; GOMES, D. D. M.; ALBUQUERQUE, E, L. S.; CRUZ, M. L. B. (Org.). Os

Recursos Hídricos do Ceará: Integração, Gestão e Potencialidades. Fortaleza: IPECE, 2011.

RODRIGUEZ, J. M. M.; SILVA, E. V.; CAVALCANTI, A. P. B. Geoecologia das paisagens: uma visão geossistêmica da análise ambiental. Fortaleza: Editora UFC, 2004.

ROSS, J. L. S. Ecogeografia do Brasil: subsídios para o planejamento ambiental. São Paulo: Oficina de Textos, 2006.

SIMPÓSIO BRASILEIRO DE GEOGRAFIA FÍSICA APLICADA, 13, Viçosa/MG. Anais... Caderno de Resumos. Universidade Federal de Viçosa, 2009.

SIMPÓSIO BRASILEIRO DE GEOGRAFIA FÍSICA APLICADA, 14, Dourados/MS. Anais... CD-ROM. Universidade Federal da Grande Dourados, 2011.

SIMPÓSIO BRASILEIRO DE GEOGRAFIA FÍSICA APLICADA, 15, Vitória/ES. Anais... CD-ROM. Universidade Federal do Espírito Santo, 2013.

SIMPÓSIO BRASILEIRO DE GEOGRAFIA FÍSICA APLICADA, 16, Teresina/PI. Anais... CD-ROM. Universidade Federal do Piauí, 2015.

SOUZA, J. C. O.; CORRÊA, A. C. B. O relevo como ponto de partida ao estudo geossistêmico da natureza: o caso da bacia hidrográfica do rio São Miguel, Alagoas. Revista GEOUECE, v. 2, n. 3, Jul./Dez., 2013.

VEYRET, Y. Os riscos: o homem como agressor e vítima do meio ambiente. São Paulo: Contexto, 2007.

\section{Agradecimentos}

Gostaríamos de externar nossos agradecimentos ao Prof. Dr. André Luiz Lopes de Faria da Universidade Federal de Viçosa e ao Laboratório de Geografia Física (LGF) da Universidade Federal da Grande Dourados por disponibilizarem, respectivamente, os anais das edições 13 e 14 do Simpósio Brasileiro de Geografia Física Aplicada. 